\title{
Ontogeny of Renal $\beta$-Adrenoceptor-Mediated Vasodilation in Sheep: Comparison between Endogenous Catecholamines
}

\author{
KENNETH T. NAKAMURA, G. PAUl MATHERNE, PEDRO A. JOSE, BETH M. ALDEN, AND \\ JEAN E. ROBILLARD \\ Departments of Pediatrics and the Cardiovascular Research Center, University of Iowa College of Medicine, Iowa \\ City, Iowa 52242 and Georgetown University Medical Center, Washington, D.C. 20007
}

\begin{abstract}
The renal hemodynamic response to renal arterial infusions of norepinephrine was compared to epinephrine infusions during renal $\alpha$-adrenoceptor blockade in chronically instrumented and unanesthetized fetal (127141 days gestation; term 145 days), newborn (6-10 days old), and nonpregnant adult sheep. Infusions of either catecholamines produced renal vasodilation which was of greater magnitude in fetal compared to newborn and adult sheep. Maximal increases in renal blood flow velocity during norepinephrine infusion were $64 \pm 5 \%$ in fetal, 23 $\pm 4 \%$ in newborn, and $24 \pm 7 \%$ in adult sheep $(p<0.001)$. Similar age-dependent increases in renal blood flow velocity were observed during epinephrine infusion, with maximal changes being $74 \pm 10 \%$ in fetal, $23 \pm 4 \%$ in newborn, and $19 \pm 4 \%$ in adult sheep $(p<0.001)$. Increases in renal blood flow velocity produced by both norepinephrine and epinephrine infusions were completely inhibited by intrarenal infusion of ICI 118,551, a $\beta_{2}$-adrenoceptor antagonist. Taken together, these results suggest that the renal vascular $\beta_{2}$-adrenergic receptor that mediates vasodilation may be stimulated by both norepinephrine and epinephrine with equal potency. In addition, results of this study demonstrate that enhanced $\beta_{2}$-adrenoceptor mediated renal vasodilatory capacity is observed during fetal life. (Pediatr Res 22: 465-470, 1987)
\end{abstract}

\section{Abbreviations}

RBF, renal blood flow

RVR, renal vascular resistance

ANOVA, analysis of variance

Extremely high catecholamine levels are observed during fetal stress (1) and during birth (2,3), with the predominant circulating catecholamine being norepinephrine. In contrast, the sympathoadrenal response to stress in adults is associated with significantly lower plasma catecholamine values where epinephrine is the major circulating catecholamine (4). Because the sympathoadrenal system plays an important role in modulating renal hemodynamics (5), knowledge about differences in sympathoadrenal activity during development and its functional role in determining $\mathrm{RBF}$ is of interest in perinatal medicine.

Received April 6, 1987; accepted May 19, 1987.

Correspondence Kenneth T. Nakamura, M.D., Department of Pediatrics, University of Iowa Hospitals, Iowa City, IA 52242.

Supported by United States Public Health Service Grants DK-38302, HD20576, HL-14388, and HD-35600. K.T.N. is the recipient of a Clinical Investigator Award HD-00670. G.P.M. is supported by NHLBI Training Grant ST32-HL07413
Little is known about the ontogeny of sympathoadrenal stimulated renal vasodilation. Buckley et al. $(6,7)$ have examined the postnatal development of renal vasodilatory mechanisms in anesthetized piglets $(6,7)$. Their studies have shown that the $\beta$ adrenergic vasodilatory mechanism in the renal vascular bed of swine is absent at birth and appears postnatally at $2 \mathrm{wk}$. However, in chronically instrumented sheep, we have demonstrated during $\alpha$-adrenoceptor blockade, enhanced renal $\beta$-adrenoceptor mediated vasodilator response to renal nerve stimulation (8) and to intrarenal infusions of epinephrine (unpublished observations) in fetal compared to newborn and adult sheep. In contrast, these results differ from dopamine-mediated vasodilator responses which are of considerably smaller magnitude in fetal, newborn, and adult sheep (9).

Since levels of plasma catecholamines and of norepinephrine, the predominant circulating catecholamine found during stress, are age dependent, and because norepinephrine and epinephrine differ in their ability to stimulate the vascular $\beta$-adrenergic receptor (10), the present protocol was designed to compare the renal hemodynamic response to renal arterial norepinephrine and epinephrine infusions during renal $\alpha$-adrenoceptor blockade in chronically instrumented fetal, newborn, and adult sheep.

\section{METHODS}

Animal preparation and surgical procedures. Fetuses of seven pregnant sheep of Dorset and Suffolk mixed breeding were studied between 127 and 141 days gestation (term was 145 days). Gestational ages were based on the induced ovulation technique as previously described (11).

Ewes were fasted for $48 \mathrm{~h}$ prior to surgery. General anesthesia of the ewe and fetal surgery were performed as previously described (11). Briefly, when the ewe was receiving a mixture of $1 \%$ halothane, $33 \%$ oxygen, and $66 \%$ nitrous oxide, the uterus was opened and bilateral femoral arterial and venous catheters were inserted. A catheter was also secured in the amniotic cavity for intrauterine pressure measurements. The left kidney was exposed through a left flank incision. A Doppler flow probe, constructed in our laboratory, was secured around the renal artery with care being taken to not interfere with renal innervation. Thereafter, a nonobstructive renal artery catheter (9) was implanted using the method described by Herd and Barger (12). The Doppler flow probe and renal arterial catheter were secured to the renal capsule.

All vascular catheters were impregnated before surgery with dimethyl-poly-siloxane (Acumetric, Elizabethtown, CT) to reduce clotting. After surgery, the ewes were kept in a restricted area and fed a standard diet. Experiments were started 3 days after surgery. Fetal weight was estimated according to the following formula: fetal body weight $(\mathrm{kg})=[0.096 \times$ gestational age (days)] $-9.233, r=0.85, p<0.001$ (13). 
Eight newborn lambs $(8.2 \pm 0.5 \mathrm{~kg})$ between the ages of 6 and 10 days and seven nonpregnant adult ewes $(53 \pm 5 \mathrm{~kg})$ were also studied. Surgery in these animals were similar to that described for the fetuses above. An additional catheter was placed in the left ventricle of the newborns and adults for infusion of radioactive microspheres to determine $\mathrm{RBF}$ in $\mathrm{ml} / \mathrm{min}$. Following surgery, the newborn lambs were returned to their mothers.

Procedures on the use of sheep in this project were approved by the University of Iowa's Animal Care and Use Committee and are in accordance with PHS policies and the Guide for the Care and Use of Laboratory Animals, NIH Publication no. 8523, revised 1985 .

Physiological studies. Each pregnant and nonpregnant ewe was transferred into a small cart permitting it to stand during the physiological studies. Each lamb was supported upright with a harness.

A 60 -min equilibration period was allowed to permit the animal to adapt to the laboratory environment and to assure stability of the preparation before starting the experiment. Arterial blood was collected from the femoral artery catheter at the beginning of each experiment to determine arterial $\mathrm{pH}$ and blood gases $\left(\mathrm{pO}_{2}, \mathrm{pCO}_{2}\right)$. During the studies, phentolamine $(4 \mu \mathrm{g} / \mathrm{kg} /$ min) was infused continuously into the renal artery at a rate of $0.1 \mathrm{ml} / \mathrm{min}$. Epinephrine and norepinephrine were diluted in D5W and given in two-fold increments, ranging from 0.0125 to $0.4 \mu \mathrm{g} / \mathrm{kg}$ of body weight. Each dose was infused directly into the renal artery as a $0.3 \mathrm{ml}$ infusion over $30 \mathrm{~s}$ using a Harvard pump. In addition, D5W was infused as a vehicle control. Doses of epinephrine and norepinephrine and D5W were administered in random sequence and each dose was given twice. There was an interval of at least $5 \mathrm{~min}$ between each dose to allow renal flow to return to baseline. Usually RBF was back to baseline 3 min after catecholamine administration. The largest catecholamine dose infused was determined by the dose that produced the maximal renal hemodynamic response without changing blood pressure and heart rate.

In a second series of experiments, done the same day and in the same animal, intrarenal catecholamine infusions were compared before and during renal arterial infusion of the $\beta_{2}$-adrenoceptor antagonist ICI 118,551 at $10 \mu \mathrm{g} / \mathrm{kg} / \mathrm{min}$.

During each experiment, arterial and amniotic pressures were recorded continuously using Statham P23Db pressure transducers (Statham Instruments, Schiller Park, IL). Fetal arterial pressure was corrected relative to a concomitant amniotic pressure. Fetal heart rate was monitored with a cardiotachometer triggered from the fetal arterial pressure pulse wave.

Changes in RBF velocity to the left kidney were monitored continuously using the ultrasonic pulsed Doppler flowmeter, modified from the original design of Hartley and Cole (14), and constructed by the University of Iowa Bioengineering Resource Facility (15). The pulsed Doppler flow probe consisted of a silastic cuff around a $1 \mathrm{~mm}$ diameter $20 \mathrm{MHz}$ piezoelectric crystal with insulated copper wire leads. The techniques for construction, use of the probes and application of the flowmeter have been validated and described in detail (15). In our model, the validity of the pulsed doppler flowmeter for use in determining percent changes $(\% \Delta)$ in fetal renal blood flow velocity has previously been demonstrated $(8,16)$.

To estimate catecholamine concentration in renal blood, baseline $\mathrm{RBF}$ in $\mathrm{ml} / \mathrm{min}$ was measured using the microspheres technique. Approximately $4.0 \times 10^{6}$ radioactive microspheres $(15 \pm$ $3 \mu \mathrm{m}$ diameter) labeled with either ${ }^{141} \mathrm{Ce},{ }^{46} \mathrm{Sc},{ }^{85} \mathrm{Sr}$, or ${ }^{95} \mathrm{Nb}(3 \mathrm{M}$ Co., Minneapolis, MN) were infused over a 30 -s period into the fetal femoral vein catheter and then immediately flushed with 3 $\mathrm{ml}$ of $0.9 \%$ saline solution $(17,18)$. In newborns and adults, radioactive microspheres were infused into the left ventricular catheter. Blood for lower body independent reference sample was collected from the femoral artery during a period of $3 \mathrm{~min}$ beginning $20 \mathrm{~s}$ before the injection of microspheres at a withdrawal rate of $2.91 \mathrm{ml} / \mathrm{min}$ using a Harvard infusion-withdrawal pump. Fetal blood collected for lower body independent reference sample was replaced with an equal volume of maternal blood to avoid any hemodynamic effect of sampling. At the end of the experiment, the animals were sacrificed with a lethal dose of pentobarbital sodium (Somlethal, Mid-Tech, Inc., Elwood, $\mathrm{KS}$ ). Animals were then weighed and kidneys were taken for radioactivity determinations.

To assess the approximate catecholamine concentration in renal blood, the catecholamine dose in $\mu \mathrm{g} / \mathrm{kg}$ was multiplied by the weight of the animal. This product, divided by blood flow $(\mathrm{ml} / \mathrm{min})$, provides an approximation of catecholamine concentration $(\mu \mathrm{g} / \mathrm{ml})$ in the renal vascular bed $(9,19)$. Estimated catecholamine concentration $(\mu \mathrm{g} / \mathrm{ml})$ was then converted to molar concentration (M).

Analytical procedures. Arterial blood for $\mathrm{pH}, \mathrm{pCO}_{2}$, and $\mathrm{pO}_{2}$ was collected anaerobically in heparinized glass syringes and measurements were immediately determined with the appropriate $\mathrm{pH}, \mathrm{pCO}_{2}$, and $\mathrm{pO}_{2}$ electrodes at $39^{\circ} \mathrm{C}$ using a Radiometer PHM 72 MK 2 acid-base analyzer (Radiometer Co., Copenhagen, Denmark).

Gamma emissions generated from the microspheres were measured in the left kidney and reference femoral arterial blood samples using a Beckman 300 gamma spectrometer. Energy window ranges were set between $74-102 \mathrm{Kev}$ for ${ }^{141} \mathrm{Ce}, 210-275$ Kev for ${ }^{85} \mathrm{Sr}, 320-410 \mathrm{Kev}$ for ${ }^{95} \mathrm{Nb}$, and $420-580 \mathrm{Kev}$ for ${ }^{46} \mathrm{Sc}$. Handling of the kidney before counting and isotopes separation were as previously described $(11,18)$.

Drugs. The following drugs were used: epinephrine (Abbott, North Chicago, IL), phentolamine (Regitine, CIBA, Summit, NJ), norepinephrine (Levophed, Winthrop-Breon, New York, NY), and ICI 118.551 (Imperial Chemical Industries, Macclesfield, Cheshire, England).

Determinations and data analysis. RBF, using the microspheres technique, was determined according to the following formula: $\mathrm{RBF}(\mathrm{ml} / \mathrm{min})=$ total kidney counts $\times$ reference flow from the femoral artery $(\mathrm{ml} / \mathrm{min}) /$ total femoral blood counts.

RVR was determined according to the following formula: $\mathrm{RVR}=\mathrm{RPP} / \mathrm{RBF}$, where RPP is the renal perfusion pressure estimated to be equal to aortic pressure minus inferior vena cava pressure.

Percent changes in renal blood flow velocity $(\% \Delta \mathrm{RBF}$, using a Doppler flow probe, were calculated using the following formula:

$$
\% \mathrm{RBF}=\left[\left(\mathrm{E}_{\mathrm{DS}}-\mathrm{B}_{\mathrm{DS}}\right) / \mathrm{B}_{\mathrm{DS}}\right] \times 100
$$

where EDS is the maximal Doppler shift in $\mathrm{KHz}$ during intrarenal epinephrine infusions; BDS is the baseline Doppler shift in $\mathrm{KHz}$.

Comparisons of dose response curves between fetal, newborn, and adult sheep were performed by simultaneous analysis of physiological dose-response curves as described by DeLean et al. (20) and previously used by us (9). These comparisons were made by using the ALLFIT program adapted for an Apple computer by Martin H. Teicher, Department of Psychiatry, Harvard Medical School. ALLFIT was made available by the Biomedical Computing Technology Information Center, Vanderbilt Medical Center, Nashville, TN. Briefly, ALLFIT analysis was based on the logistic function:

$$
y=\frac{a-d}{1+(x / c)^{b}}+d
$$

where $x$ and $y$ were the dose and response respectively; and " $a$," "b," "c," and " $d$ " were the four fitted parameters: response at zero dose ("a"), slope factor ("b"), ED ED $_{50}$ ("c"), and response at "infinite" dose ("d"). Goodness of fit of individual dose-response curves was evaluated by: 1) $\mathrm{F}$ ratio test which represented the ratio of residual variance for one curve to the overall residual variance of the other curves, and 2) run test, which evaluated the randomness of distribution of data points around and along the 
fitted curve. Significant $\mathrm{F}$ ratio tests $(p<0.05)$ or run tests $(p<$ $0.05)$ suggested poor fits according to the logistic model. Consequences of forcing parameters to be equal were also evaluated by an $\mathrm{F}$ ratio test. A significant $p$ value of less than 0.05 indicated that data supported the hypothesis that shared parameters were in fact different from each other.

One-way ANOVA with Newman-Keuls multiple comparisons procedure was used to compare baseline parameters. Systemic hemodynamic measurements were analyzed by ANOVA for repeated measures and comparisons to a control were made using Dunnett's test. The term "significant" is used throughout

Table 1. Baseline renal and systemic hemodynamic values $(\text { mean } \pm S E)^{*}$

\begin{tabular}{lccc}
\hline & $\begin{array}{c}\text { Fetus } \\
(n=7)\end{array}$ & $\begin{array}{c}\text { Newborn } \\
(n=8)\end{array}$ & $\begin{array}{c}\text { Adult } \\
(n=9)\end{array}$ \\
\hline $\mathrm{RBF}$ & & & \\
$\mathrm{ml} / \mathrm{min}$ & $23 \pm 3 \dagger$ & $83 \pm 26 \ddagger$ & $381 \pm 55 \S$ \\
$\mathrm{ml} / \mathrm{min} / \mathrm{gKw}$ & $1.76 \pm 0.13$ & $3.14 \pm 0.91$ & $4.52 \pm 0.80 \S$ \\
$\mathrm{RVR}$ & & & \\
$\mathrm{mm} \mathrm{Hg} / \mathrm{ml} / \mathrm{min}$ & $2.09 \pm 0.23$ & $1.39 \pm 0.26 \ddagger$ & $0.22 \pm 0.03 \S$ \\
$\mathrm{mm} \mathrm{Hg} / \mathrm{ml} / \mathrm{min} / \mathrm{gKw}$ & $25.90 \pm 2.15$ & $36.84 \pm 8.36$ & $19.26 \pm 3.87$ \\
$\mathrm{MABP} \mathrm{mm} \mathrm{Hg}$ & $46 \pm 2 \dagger$ & $79 \pm 3$ & $86 \pm 11 \S$ \\
$\mathrm{HR}$ beats $/ \mathrm{min}$ & $176 \pm 6 \dagger$ & $200 \pm 11$ & $97 \pm 8 \S$ \\
\hline
\end{tabular}

* RBF, renal blood flow to left kidney; RVR, renal vascular resistance in left kidney; MABP, mean arterial blood pressure; $\mathrm{HR}$, heart rate; $\mathrm{gKw}$, gram kidney weight.

$\dagger$ Values statistically different from newborn $(p<0.05)$

$\ddagger$ Values statistically different from adults $(p<0.05)$.

$\S$ Values statistically different from fetus $(p<0.05)$. to describe changes with a total $p$ value of less than 0.05 in a two-sided significance limit. Values are expressed as means \pm SEM.

\section{RESULTS}

Baseline arterial blood $\mathrm{pH}, \mathrm{pCO}_{2}(\mathrm{~mm} \mathrm{Hg}), \mathrm{pO}_{2}(\mathrm{~mm} \mathrm{Hg})$, and hematocrit (\%) were $7.39 \pm 0.05,48 \pm 4,20 \pm 2$, and $30 \pm$ $2 ; 7.40 \pm 0.01,32 \pm 2,101 \pm 8$, and $24 \pm 1 ; 7.47 \pm 0.02,29 \pm$ $1,103 \pm 2$, and $22 \pm 1$ in fetal $(n=7)$, newborn $(n=8)$, and adult $(n=7)$ sheep, respectively.

Baseline renal hemodynamics and mean arterial blood pressure values in fetal, newborn and adult sheep are presented in Table 1 . RBF values measured by the microsphere technique increased with maturation, being lower in fetuses than in newborn or adult sheep when expressed in $\mathrm{ml} / \mathrm{min}(\mathrm{F}=50, p<$ $0.05)$. When corrected for kidney weight $(\mathrm{ml} / \mathrm{min}$ per g kidney weight), only fetal values were lower than values in adults $(\mathrm{F}=$ $5.5, p<0.05)$. Moreover, $\mathrm{RVR}$ was significantly higher in fetal and newborn compared to adult sheep $(\mathrm{F}=15.6, p<0.05)$, and declined progressively with age. However, when RVR was corrected for kidney weight, RVR tended to be higher in fetuses and in newborn compared to adult sheep, but differences were not found to be significant $(\mathrm{F}=3.3, p=0.08)$.

Effect of intrarenal catecholamine infusions on blood pressure and heart rate. Intrarenal infusions of norepinephrine had no effect on the systemic circulations of fetal, newborn or adult sheep (Fig. 1). Mean arterial blood pressure and heart rate did not vary during renal artery infusions of different norepinephrine concentrations. Similarly, renal arterial infusions of epinephrine (Fig. 2) had no effect on mean arterial blood pressure. A signifi-
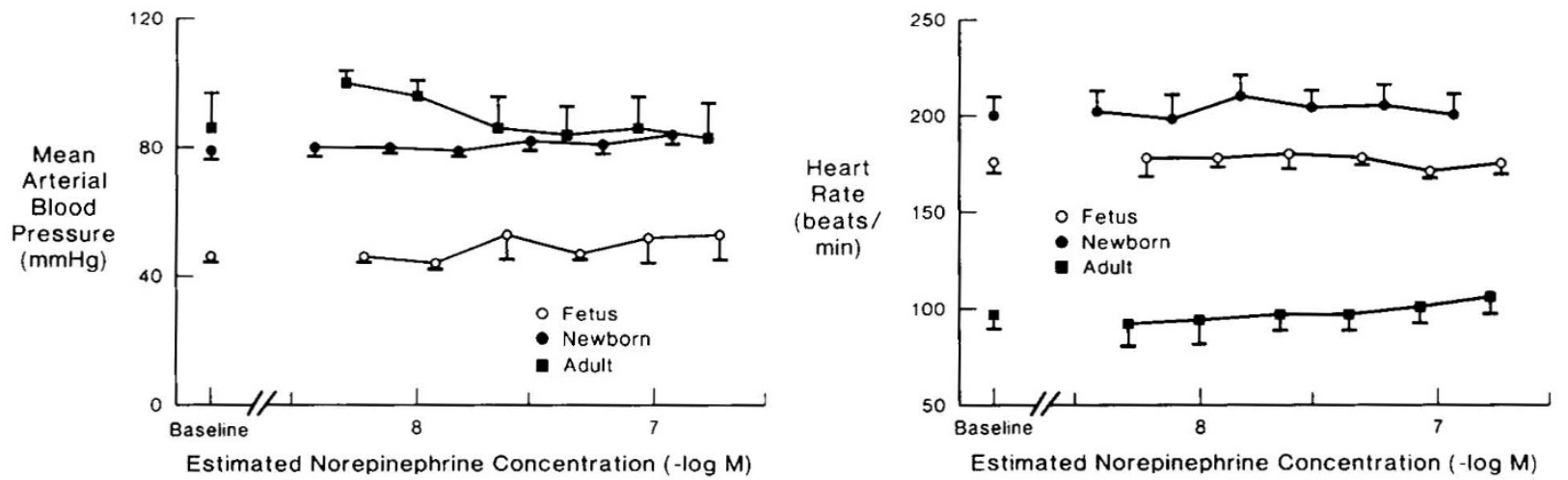

Fig. 1. Mean arterial blood pressure and heart rate during intrarenal norepinephrine infusions. Values are means $\pm \mathrm{SE}$. Baseline refers to placebo infusion of vehicle. Phentolamine infused intrarenally at $4 \mu \mathrm{g} / \mathrm{kg} / \mathrm{min}$. No differences were noted in mean arterial blood pressure or heart rate when different doses, including placebo, were compared ( $p>0.05$ ANOVA).
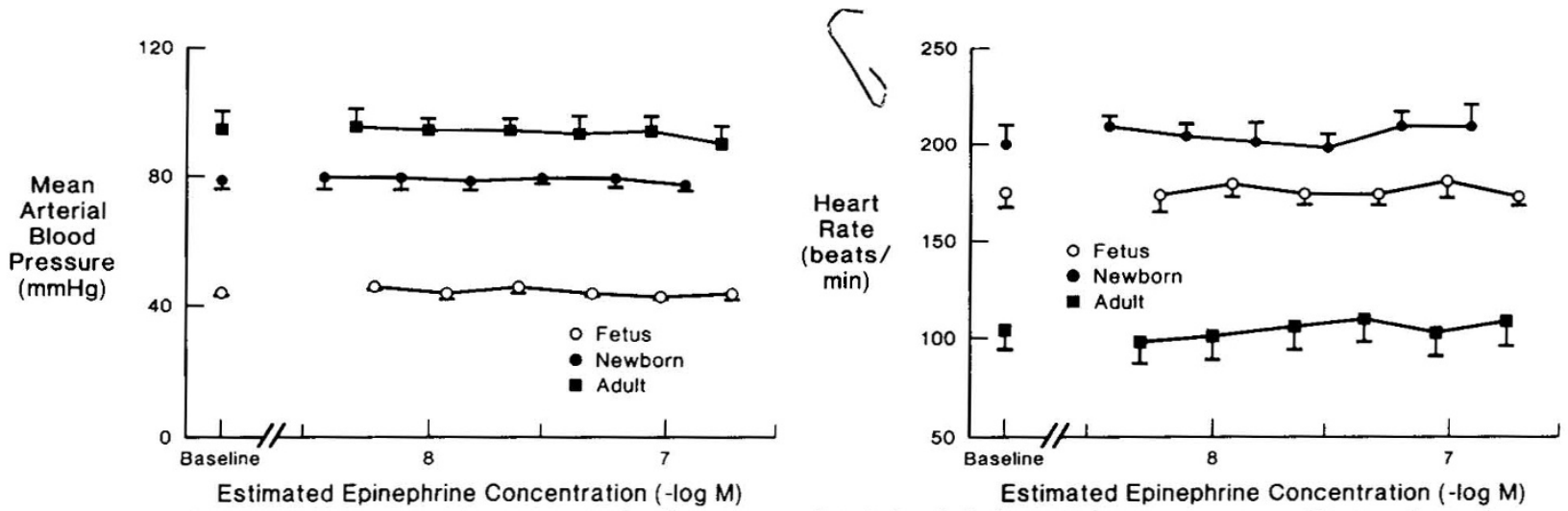

Fig. 2. Mean arterial blood pressure and heart rate during intrarenal epinephrine infusions. Values are means \pm SE. Baseline refers to placebo infusion of vehicle. Phentolamine infused intrarenally at $4 \mu \mathrm{g} / \mathrm{kg} / \mathrm{min}$. No differences were noted in mean arterial blood pressure or heart rate when different doses were compared to baseline ( $p>0.05$, Dunnett). 
cant overall difference in heart rate of adult sheep was noted during renal arterial epinephrine infusions (ANOVA, $p<0.05$ ). However, no difference was noted between vehicle infusion and each dose of epinephrine (Dunnett, $p>0.05$ ).

Effect of intrarenal catecholamine infusions on percent change

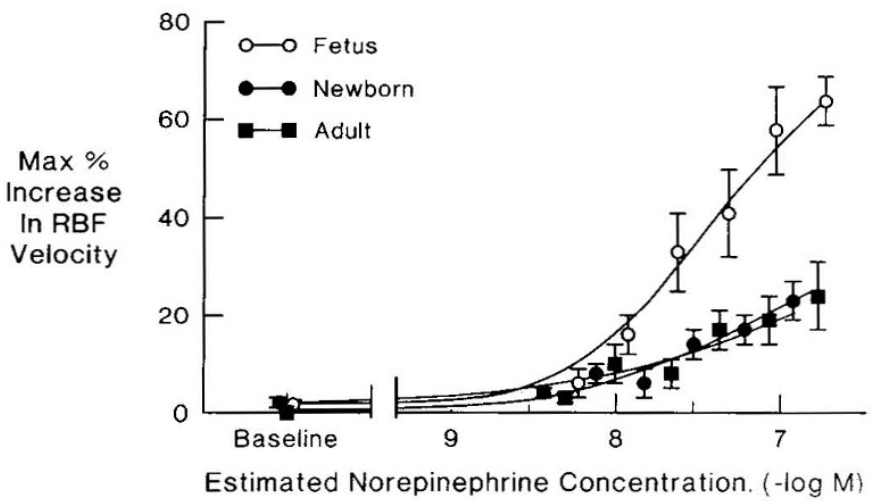

Fig. 3. Effect of intrarenal norepinephrine infusion on $\%$ changes in $\mathrm{RBF}$ velocity during $\alpha$-adrenoceptor blockade. Values are means $\pm \mathrm{SE}$. Baseline refers to placebo infusion of vehicle. $\alpha$-Adrenoceptor antagonist, phentolamine, was infused intrarenally at $4 \mu \mathrm{g} / \mathrm{kg} / \mathrm{min}$. The maximum response of the fetal dose response curve differed from both newborn and adult sheep $(p<0.001)$.

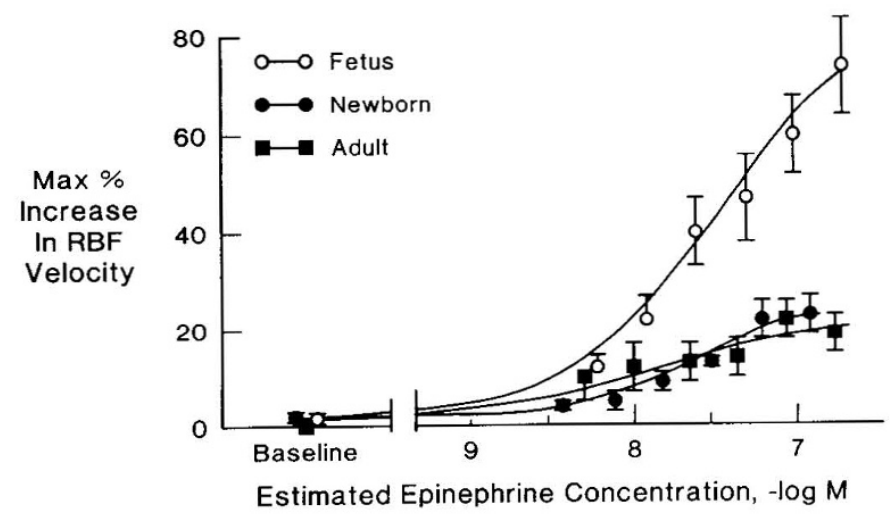

Fig. 4. Effect of intrarenal epinephrine infusions on $\%$ changes in $\mathrm{RBV}$ velocity during $\alpha$-adrenoceptor blockade. Values are means $\pm \mathrm{SE}$. Baseline refers to placebo infusion of vehicle. $\alpha$-Adrenoceptor antagonist, phentolamine, was infused intrarenally at $4 \mu \mathrm{g} / \mathrm{kg} / \mathrm{min}$. The slope, effective dose producing a $50 \%$ increase in flow velocity and maximum response of the fetal dose response curve each differed from newborn and adult sheep $(p<0.001)$. in mean $R B F$ velocity during renal $\alpha$-adrenoceptor blockade. During intrarenal infusion of phentolamine, no changes in blood pressure and heart rate were observed. Renal vasoconstriction produced by norepinephrine and epinephrine was completely inhibited during renal $\alpha$-adrenoceptor blockade. Moreover, intrarenal norepinephrine infusions produced renal vasodilation in fetal, newborn and adult sheep (Fig. 3). A dose-response relation was noted in fetal (goodness-of-fit $\mathrm{F}=1.79, p=0.498$ ), run test $p>0.05$ ), newborn (goodness-of-fit $\mathrm{F}=0.38, p=0.290$, run test $p>0.05$ ), and adult sheep (goodness-of-fit $\mathrm{F}=1.16, p=0.798$, run test $p>0.05$ ). No differences in minimum response, slope, $\mathrm{ED}_{50}$, and maximum response were noted between newborn and adult sheep $(\mathrm{F}=0.18, p=0.983)$. However, the maximum response of the fetal dose response curve was greater when compared to newborn and adult sheep, with maximal increases in RBF velocity being $64 \pm 5 \%$ in fetal, $23 \pm 4 \%$ in newborn, and $24 \pm 7 \%$ in adult sheep, respectively ( $\mathrm{F}=44.4, p<0.001)$.

Renal arterial infusions of epinephrine also produced dose related increases in RBF velocity in fetal (goodness-of-fit $F=$ $3.02, p=0.232$, run test $p>0.05$ ), newborn (goodness-of-fit $\mathrm{F}$ $=0.12, p=0.03$, run test $p>0.05$ ) and adult sheep (goodnessof-fit $\mathrm{F}=1.03, p=0.888$, run test $p>0.05$ ) (Fig. 4). However, the best fit was generated by sharing the four fitted parameters (minimum response, slope, $\mathrm{ED}_{50}$, and maximum response) between newborn and adult curves $(\mathrm{F}=1.43, p=0.302)$ and concluding that the slope, $\mathrm{ED}_{50}$, and maximum vasodilation to epinephrine was different in fetuses compared to newborn and adult sheep. Maximal increases in RBF velocity to intrarenal epinephrine infusions were $74 \pm 10 \%$ in fetal, $23 \pm 4 \%$ in newborn, and $19 \pm 4 \%$ in adult sheep, respectively ( $\mathrm{F}=57.8, p$ $<0.001$ ).

Comparisons between norepinephrine and epinephrine mediated renal vasodilation (Fig. 5). To test the hypothesis that the measured renal vasodilatory response to norepinephrine might differ from epinephrine during renal $\alpha$-adrenoceptor blockade, comparisons of renal vasodilatory dose-response relations were made between norepinephrine and epinephrine in fetal, newborn, and adult sheep. In fetuses, norepinephrine and epinephrine dose response curves were best fitted by equating responses at zero dose, slopes, and maximal responses $(\mathrm{F}=0.63, p=0.62)$. Norepinephrine was slightly less potent than epinephrine with a ratio of effective dose producing a $50 \%$ increase in RBF velocity, $\mathrm{ED}_{50}$ norepinephrine/ $\mathrm{ED}_{50}$ epinephrine of $1.5 \pm 0.2$. In contrast, comparisons of renal vasodilatory responses between norepinephrine and epinephrine in both newborn and adult sheep revealed similar dose-response curves $(\mathrm{F}=0.42, p=0.74$ and $\mathrm{F}$ $=1.45, p=0.32$ in newborn and adult sheep, respectively).

Effect of intrarenal $\beta$-adrenoceptor antagonists on catecholamine induced renal vasodilation during renal $\alpha$-adrenoceptor blockade. As shown in Figure 6, renal vasodilation produced by exogenous administration of norepinephrine was inhibited by ICI 118,551 . Similar blockade by ICI 118,551 was observed in all age groups (fetus, $n=4$; newborn, $n=4$, adult, $n=4$ ).
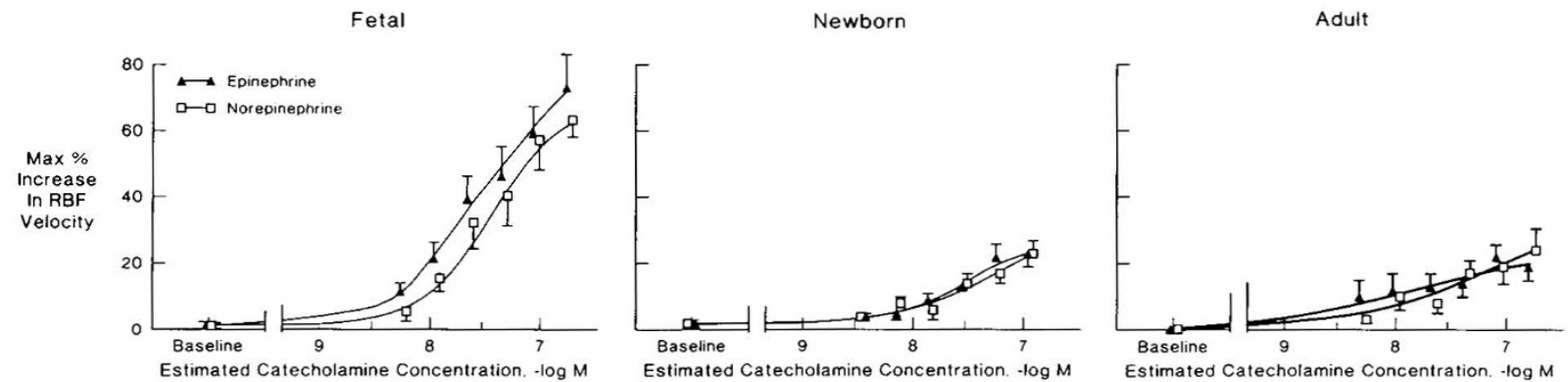

Fig. 5. Comparison between norepinephrine and epinephrine mediated renal vasodilation in fetal newborn and adult sheep. Values are means \pm SE. Baseline refers to placebo infusion of vehicle. $\alpha$-Adrenoceptor antagonist, phentolamine, was infused intrarenally at $4 \mu \mathrm{g} / \mathrm{kg} / \mathrm{min} . \mathrm{In}$ fetuses, the $\mathrm{ED}_{50}$ norepinephrine/ED $\mathrm{ED}_{50}$ epinephrine $=1.5 \pm 0.2$. Dose response curves in newborn and adult sheep were similar. 


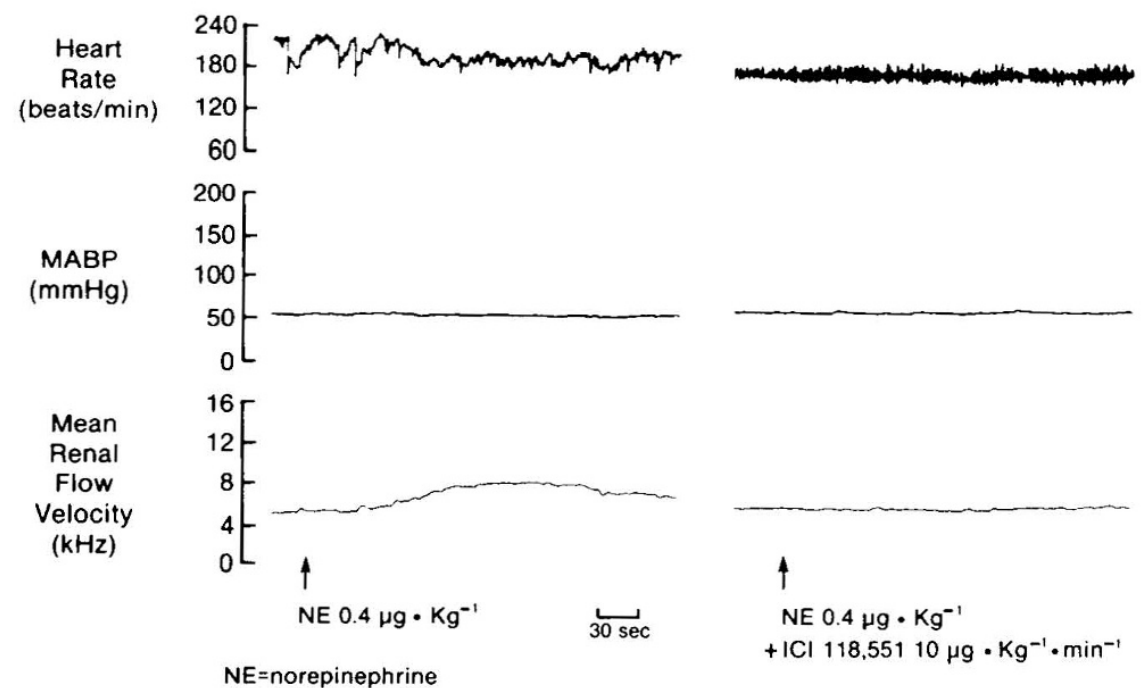

Fig. 6. Effect of ICI 118,551 on norepinephrine mediated renal vasodilation during intrarenal phentolamine intusion in a fetal lamb (135 days gestation). Arrows indicate start of infusion. Phentolamine infusion $=4 \mu \mathrm{g} / \mathrm{kg} / \mathrm{min}$. $M A B P$, mean arterial blood pressure.

\section{DISCUSSION}

The present study demonstrates that intrarenal infusion of endogenous catecholamines during $\alpha$-adrenoceptor blockade produces renal vasodilation which is of greater magnitude in fetuses than in newborn and adult sheep. These results are consistent with our previous study demonstrating enhanced renal vasodilatory response to renal nerve stimulation during renal $\alpha$ adrenergic receptor blockade in fetal sheep (8). Renal arterial infusion of propranolol, a nonspecific $\beta$-adrenoceptor antagonist, and ICI 118,551 , a highly specific and potent $\beta_{2}$-adrenoceptor antagonist, inhibited the renal vasodilation produced by renal nerve stimulation without changing systemic hemodynamics or baseline mean RBF velocity (8). Taken together, these results provide evidence for an age-dependent renal $\beta$-adrenergic vasodilator mechanism during development in sheep.

It is important to note that norepinephrine is capable of stimulating vasodilatory $\beta$-adrenoceptors in the renal vascular bed since norepinephrine is the predominant circulating catecholamine during fetal stress (1), including birth $(2,3)$, and that increased activity of the peripheral sympathetic nervous system, via release of neuronal norepinephrine, plays a major role in the renal hemodynamic response to stress during fetal life (21). Thus, activation of renal vascular $\beta$-adrenergic receptors that mediate vasodilation may occur with stimulation by any of three functional components of the sympathoadrenal system, i.e. sympathetic nerve activity, circulating norepinephrine and epinephrine.

Renal vasodilatory responses are expected with epinephrine infusions according to classical theory of $\beta_{2}$-adrenoceptor stimulation, since epinephrine is both a $\beta_{1}$ - and $\beta_{2}$-adrenoceptor agonist (10). In contrast, the vasodilation observed during norepinephrine infusion is unexpected since norepinephrine is felt to have little action on vasodilatory $\beta_{2}$-adrenoceptors (10). However, we have previously demonstrated that postsynaptic $\beta_{2^{-}}$ adrenoceptors are innervated in the near term fetus (8) and during renal $\alpha$-adrenoceptor blockade, stimulation of renal sympathetic nerves produce renal vasodilation presumably by release of the neurotransmitter, norepinephrine.

In addition, recent studies suggest that norepinephrine-mediated peripheral vasodilation may be more common than previously thought. Vatner et al. (22) have demonstrated norepinephrine-induced $\beta_{1}$-adrenergic peripheral vasodilation in conscious dogs. McPherson et al. (23) have shown that norepinephrine as well as epinephrine infusions in the presence of $\alpha$ adrenergic blockade, produce dilator responses in anesthetized cats. Hyman and Kadowitz (24) have evidence supporting norepinephrine stimulation of $\beta_{2}$-adrenoceptors in the pulmonary vascular bed of the cat. Finally, Taira et al. (25) using anesthetized dogs, demonstrated both $\beta_{1}$ - and $\beta_{2}$-adrenoceptor mediated vasodilatory responses in the renal vascular bed. The possibility that $\beta_{1}$-adrenoceptors may also mediate the renal vasodilation observed was not investigated in the present study. However, since $100 \%$ of renal vasodilation produced by both norepinephrine and epinephrine infusions were inhibited by ICI 118,551, a specific $\beta_{2}$-adrenoceptor antagonist (26), it seems unlikely that activation of fully differentiated $\beta_{1}$-adrenoceptors have a major role in mediating the vasodilatory responses observed.

Reasons to explain these observations may be offered. $\beta_{2-}$ Adrenergic receptor density may be greater in fetal renal vessels compared to vessels from newborn and adult sheep. In support of this hypothesis is the preliminary report suggesting that renal cortical membranes (containing both vascular and tubular membranes) from fetal kidneys contains a greater density of $\beta_{2}$ adrenoceptors than kidneys from adults (27). Moreover, stereoselectivity of the $\beta$-adrenoceptor was greater in adult than fetal renal cortical membranes suggesting that $\beta$-adrenoceptors may be less differentiated into specific $\beta$-adrenoceptor subtypes in immature animals (27).

In summary, renal arterial catecholamine infusions during renal $\alpha$-adrenoceptor blockade produce greater renal vasodilation in fetal compared to newborn and adult sheep. Also norepinephrine-mediated renal vasodilation is similar to that produced by epinephrine infusions and this vasodilation is blocked by infusion of a specific $\beta_{2}$-adrenoceptor antagonist.

Acknowledgments. The authors appreciate the generous supplies of phentolamine from Ciba Pharmaceutical Company, Summit, NJ and ICI 118,551 from Imperial Chemical Industries, Macclesfield, Cheshire, England.

\section{REFERENCES}

1. Cohen WR, Piasecki GJ, Jackson BT 1982 Plasma catecholamines during hypoxemia in fetal lamb. Am J Physiol 243:R520-R525

2. Lagercrantz $\mathrm{H} 1984$ Catecholamine surge at birth in the human infant. In: Catecholamines: Basic and Peripheral Mechanisms. Alan R Liss, Inc., New York, pp 113-120

3. Padbury JF, Diakomanolis ES, Hobel CJ, Perelman A, Fisher DA 1981 Neonatal adaptation: sympatho-adrenal response to umbilical cord cutting. Pediatr Res 15:1483-1487

4. Wortsman J, Frank S, Cryer PE 1984 Adrenomedullary response to maximal stress in humans. Am J Med 77:779-784

5. Insel PA, Snavely MD 1981 Catecholamines and the kidney: receptors and renal function. Ann Rev Physiol 43:625-636

6. Buckley NM, Brazeau P, Gootman PM, Frasier ID 1979 Renal circulatory effects of adrenergic stimuli in anesthetized piglets and mature swine. Am J Physiol 237:H690-H695

7. Buckley NM, Brazeau P, Charney AN, Cabili S, Feldman G, Garvey M, Frasier 
ID 1984 Cardiovascular and renal effects of isoproterenol infusions in young swine. Bio Neonate 45:69-77

8. Robillard JE, Nakamura KT, Wilkin MK, McWeeny OJ, DiBona GF 1987 Ontogeny of the renal hemodynamic response to renal nerve stimulation in sheep. Am J Physiol 252:F605-F612

9. Nakamura KT, Felder RA, Jose PA, Robillard JE 1987 Effects of dopamine in the renal vascular bed of fetal, newborn and adult sheep. Am J Physiol 252:R490-R497

10. Weiner N 1985 Norepinephrine, epinephrine and the sympathomimetic amines. In: Gilman AG, Goodman LS, Rall TW, Murad F (eds) The Pharmacological Basis of Therapeutics. MacMillan, New York, pp 145-180

11. Robillard JE, Weitzman RE 1980 Developmental aspects of the fetal renal response to exogenous arginine vasopressin. Am J Physiol 238:F407-F414

12. Herd JA, Barger AC 1964 A simplified technique for chronic catheterization of blood vessels. J Appl Physiol 19:791-792

13. Robillard JE, Matson JR, Sessions C, Smith FG Jr 1979 Developmental aspects of renal tubular reabsorption of water in the lamb fetus. Pediatr Res 13:11721176

14. Hartley CJ, Cole JS 1974 An ultrasonic pulsed doppler system for measuring blood flow in small vessels. J Appl Physiol 37:626-629

15. Haywood JR, Shaffer RA, Fastenow C, Fink GD, Brody MJ 1981 Regional blood flow measurement with pulsed doppler flowmeter in the conscious rat. Am J Physiol 241:H273-H278

16. Robillard JE, Nakamura KT, DiBona GF 1986 Effects of renal denervation on renal responses to hypoxemia in fetal lambs. Am J Physiol 250:F294F301

17. Heymann MA, Payne BD, Hoffman JIE, Rudolph AM 1977 Blood flow measurements with radionuclide-labeled particles. Prog Cardiovasc Dis 20:55-79
18. Robillard JE, Weitzman RE, Burmeister L, Smith FG Jr 1981 Developmental aspects of the renal response to hypoxemia in the lamb fetus. Circ Res 48:128-138

19. Manders WT, Pagani M, Vatner SF 1979 Depressed responsiveness to vasoconstrictor and dilator agents and baroreflex sensitivity in conscious, newborn lambs. Circulation 60:945-955

20. DeLean A, Munson PJ, Rodbard D 1978 Simultaneous analysis of families of sigmoidal curves: application to bioassay, radioligand assay, and physiological dose-response curves. Am J Physiol 253:E97-E102

21. Schuijers JA, Walker DW, Browne CA, Thorburn GD 1986 Effect of hypoxemia on plasma catecholamines in intact and immunosympathectomized fetal lambs. Am J Physiol 251:R893-R900

22. Vatner SF, Knight DR, Hintze TH 1985 Norepinephrine-induced $\beta_{1}$-adrenergic peripheral vasodilation in conscious dogs. Am J Physiol 249:H49-H56

23. McPherson GA, Malta E, Raper C 1981 Effects of some catecholamines on the cat cardiovascular system: interactions with adrenoceptor antagonists. J Cardiovasc Pharmacol 3:739-752

24. Hyman AL, Kadowitz PJ 1986 Enhancement of $\alpha$ - and $\beta$-adrenoceptor responses by elevations in vascular tone in pulmonary circulation. Am J Physiol 250:H1109-H1116

25. Taira N, Yabuuchi Y, Yamashita S 1977 Profile of $\beta$-adrenoceptors in femoral, superior mesenteric and renal vascular beds of dogs. Br J Pharmacol 59:577583

26. Bilski AJ, Halliday SE, Fitzgerald JD, Wale JL 1983 The pharmacology of a $\beta_{2}$-selective adrenoceptor antagonist (ICI 118,551). J Cardiovasc Pharmacol 5:430-437

27. McKelvey T, Felder C, Nakamura K, Robillard J, Jose P 1987 Multiple $\beta$ adrenoceptors are present in adult but not fetal sheep kidneys. Pediatr Res $21: 218 \mathrm{~A}$ (abstr) 